\title{
TRANSIENT RESPONSE OF LONG BUBBLES IN VOLATILE ORGANIC COMPOUNDS
}

\author{
Cheng-Hsing Hsu \\ Department of Mechanical Engineering, Chung-Yuan Christian University, Chung Li, Taiwan, R.O.C. \\ Ching-Chuan Chang \\ Department of Mechanical Engineering, Chung-Yuan Christian University, Chung Li, Taiwan, R.O.C., \\ nashsccc8142@yahoo.com.tw \\ Chia-Chuan Kuo \\ Department of Mechanical Engineering, Chung-Yuan Christian University, Chung Li, Taiwan, R.O.C. \\ Kuang-Yuan Kung \\ Department of Mechanical Engineering, Nanya Institute of Technology, Chung Li, Taiwan, R.O.C.
}

Follow this and additional works at: https://jmstt.ntou.edu.tw/journal

Part of the Engineering Commons

\section{Recommended Citation}

Hsu, Cheng-Hsing; Chang, Ching-Chuan; Kuo, Chia-Chuan; and Kung, Kuang-Yuan (2011) "TRANSIENT RESPONSE OF LONG BUBBLES IN VOLATILE ORGANIC COMPOUNDS," Journal of Marine Science and Technology. Vol. 19: Iss. 5, Article 10.

DOI: $10.51400 / 2709-6998.2168$

Available at: https://jmstt.ntou.edu.tw/journal/vol19/iss5/10

This Research Article is brought to you for free and open access by Journal of Marine Science and Technology. It has been accepted for inclusion in Journal of Marine Science and Technology by an authorized editor of Journal of Marine Science and Technology. 


\title{
TRANSIENT RESPONSE OF LONG BUBBLES IN VOLATILE ORGANIC COMPOUNDS
}

\author{
Cheng-Hsing Hsu*, Ching-Chuan Chang*, Chia-Chuan Kuo*, \\ and Kuang-Yuan Kung**
}

Key words: bubble, evaporation, gases, transient response.

\begin{abstract}
A mass flow controller (MFC) was used to control the injection gas amount into volatile organic compounds (VOCs), each having a different evaporation rate, within straight tubes. As the moving velocities of the air bubbles within the straight tube had changed, a specific transient response occurred. The transient shape was a mushroom bubbles. From the experiment results, as the evaporation rate of VOCs $\geqq 1$, mushroom bubbles occur as the Reynolds number (Re) of the moving air bubbles reach a certain region. Moreover, the shapes mushroom bubbles were more apparent when volatility of the solvent was higher. As VOCs evaporation rate $<1$, the mushroom bubble phenomenon did not occur, regardless how the Re values of the moving air bubbles had changed. When the Re values for acetone, methyl alcohol and butyl acetate were between 4381 4430, 2460 2490 and 1940 1980, respectively, the transient response phenomenon occurred.
\end{abstract}

\section{INTRODUCTION}

VOCs are commonly seen chemicals at work sites; its chemical solvents can easily dissolve other raw materials or substances. Since the solvents are required in many applications, they are broadly used at work sites. Besides the purpose of dissolving raw materials or substances, most of the solvents have a high volatile rate, which leave little to no residue on materials. This property allows VOCs to be applied in the coating materials of metals and plastics, the removal of grease on shaft bearings, the maintenance for machinery joints, etc., and furthermore to serve as diluents, detergents, grease re-

Paper submitted 11/03/09; accepted 07/02/10. Author for correspondence: Ching-Chuan Chang (e-mail: nashsccc8142@yahoo.com.tw).

*Department of Mechanical Engineering, Chung-Yuan Christian University, Chung Li, Taiwan, R.O.C.

**Department of Mechanical Engineering, Nanya Institute of Technology, Chung Li, Taiwan, R.O.C. movers, fuel, and even medical reagents Lalanne et al. [12]. In general, VOCs include the following properties: A high Henry's constant, low polarity, low permeability, low lipid solubility, high vapor pressures, small molecular weights, toxic properties, and have shorter half lifetimes. There are numerous studies regarding VOCs in waste water treatment, soil contamination, volatile behavior of building materials $[9$, $10,15]$.

The studies about a long bubble penetrating through Newtonian fluid in the horizontal tube have been for several years. The earliest studies of the penetration of a long bubble in a tube filled with a viscous fluid was completed by Fairbrother and Stubbs [3]. The interaction between the bubble and the Newtonian fluid was studied by observing the gas injected into a tube filled with Newtonian fluid. An empirical formula between $\mathrm{m}$ and $\mathrm{Ca}$ was obtained experimentally.

$$
m=\frac{\left(u_{b}-u\right)}{u_{b}}=1.0 C a^{\frac{1}{2}}=\left(\frac{\mu \times u_{b}}{\sigma}\right)^{\frac{1}{2}}
$$

where $u_{b}$ is the velocity of the bubble, $u$ is the velocity, $\sigma$ is the surface tension, $\mu$ is the viscosity of the fluid. $\mathrm{Ca}$ is the Capillary number, ranged as $10^{-5} \leq C a \leq 10^{-2}$.

Saffman and Geofffrey Taylor [17] studied the penetration of water into a Hele-Shaw cell filled with oil at slow speed. The hollow ratio is defined by the ratio of the diameter of the bubble to that of the tube. Taylor [20] obtained a correlated curve of the fractional coverage to the capillary number by using three different diameter circular tubes with various fluids. Three possible fluid flow patterns were predicted including two kinds of re-circulating flows with a low capillary number if $m<0.5$ and one by-pass flow with a high capillary number $m>0.5$. A numerical solution of the momentum equations of the bubble motion by neglecting the gravity and inertia terms was proposed by Cox $[1,2]$. They indicated that the fractional coverage approaches an asymptotic value $m=$ 0.6 , which is close to the value $m=0.55$ estimated in Taylor's [20] experiment, as $C a$ approaching the value of 10 . The final size and shape is reached at the position 1.5 times of the diameter trailing away from the tip of the front tip of the bubble 
in the result of their observing. A theoretical shape equation of the bubble front showed as Eq. (2) by Pitts [16].

$$
\exp \left(\frac{\pi x}{2 \lambda}\right) \cos \left(\frac{\pi y}{2 \lambda}\right)=1
$$

which fits the experimental results for $\lambda<0.77$.

Schwartz et al. [18] reported that $\lambda$ is a function of the capillary number only by observing the profile of the bubble and the residual fluid in a capillary. It was consistent with the result of the result of Taylor [20]. Kolb and Cerro [11] found that the value of the fractional coverage reaches an asymptotic value $m=0.64$, which was close to the asymptotic value $m=$ 0.6 suggested by Cox [1], with an higher capillary number by observing the long bubble in a square tube filled with a Newtonian fluid. Wong et al. [21,22] proposed a shape equation of the bubble front for the rectangular tube by studying the long bubble penetration in a rectangular tube filled with viscous fluids experimentally and theoretically. It is similar to the equation proposed by Pitts [16].

Huzyak and Koelling [8] indicated that the fractional coverage is only related to the capillary number for the Newtonian fluids, but is the function of both the capillary number and inner diameter of the tube for viscoelastic fluids by their experimental studying. Giavedoni and Saita [5] studied the influences of the capillary number and the Reynolds number on the fluid film thickness for two-dimensional and axisymmetric cases by numerical method. Gauri and Koelling [4] measured the flow field near the bubble tip using the Particle Tracking Velocimetry (PTV) technique and presented the two typical flow patterns suggested by Taylor [20]. Hsu et al. [7] showed ranges of the three flow patterns suggested by Taylor [20] by using a finite difference method (FDM) with successive overrelaxation (SOR). Yamamoto et al. [23] studied the effect of $\mathrm{Ca}$ and Weiseenberg number (Wi) on $m$ for the Newtonian and non- Newtonian fluid experimentally.

In previous studies regarding long bubbles, there were few discussions where VOCs were used as the test fluid. In this experiment four different types of VOCs, acetone, methyl alcohol, butyl acetate and n-pentyl alcohol, were used to study long bubbles, full with VOC liquid in a straight tube. By controlling the gas flow rates through MFC, the temporary status of the VOCs, due to the changing of the gas flow rates, were observed and discussed. In this paper, the various dimensionless parameters of the VOCs and the shape changes of the air bubbles were discussed. In addition, the study defined an empirical equation for the air bubble shapes, which was to depict the bubble shape formations by VOCs.

\section{EXPERIMENT}

\section{Experimental}

The schematic drawing of this experimental system is shown in Fig. 1. It is setup by some appropriate modification

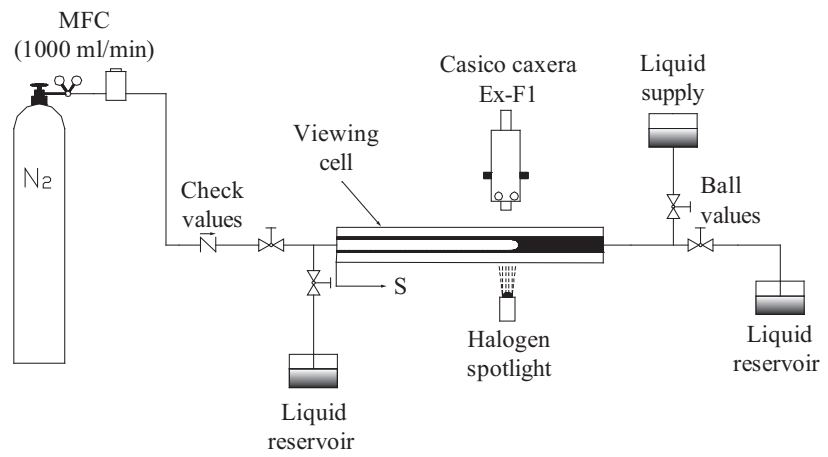

Fig. 1. Experimental system.

from that of Huzyak and Koelling [8]. The images of the bubble are captured by a high-speed camera (CASIO EX-F1) with 6 Mega pixel/60 frames per second. The Coaxial light source (LA180-Me) is used as the light source in this experiment. The pressure is $10 \mathrm{~kg} / \mathrm{cm}^{2}$ at the entrance. Nitrogen with $99.99 \%$ purity is selected to be the most suitable injection gas in this experiment. The volume rate of the injection gas was controlled by a mass flow controller. The gas is injected with three volume rates, such as $1000 \mathrm{ml} / \mathrm{min}, 800 \mathrm{ml} / \mathrm{min}$ and $600 \mathrm{ml} / \mathrm{min}$. The tube is made of high-hardness heat-resistant glass. The glass frame with a dimension of $50 \mathrm{~mm} \times 50 \mathrm{~mm} \times$ $1000 \mathrm{~mm}$, and the gap between the frame and the tube is filled with glycerin to reduce the effect of the refraction. A ruler is affixed on the frame for the convenience to calculate the velocity of the bubble.

\section{Fluid Properties}

According to the definition from U.S. EPA (standard vapor pressure at $25^{\circ} \mathrm{C}$ ): VVOC (Very Volatile Organic Compounds): Vapor pressure $>380 \mathrm{mmHg}$; VOC (Volatile Organic Compounds): $10^{-1} \mathrm{mmHg}<$ Vapor pressure $<380 \mathrm{mmHg}$; SVOC (Semi Volatile Organic Compounds): Vapor pressure $<10^{-1}$ $\mathrm{mmHg}$; NVOC (Non- Volatile Organic Compounds): Vapor pressure $<10^{-7} \mathrm{mmHg}$. The above standards are suitable for the determination of high concentration or purity for organic substances. When the organic compound is a pure substance, its volatility could be just simply determined by its vapor pressure. Makcay and Leinonen [13] used the relation between the Henry's constant and volatility, and classified the substances according to the Henry's constant. When the Henry's constant $\left(\mathrm{atm}-\mathrm{m}^{3} / \mathrm{mole}\right)>10^{-3}$, the compound was considered a high volatile compound, where the transport resistance was completely controlled by the liquid phase; when the Henry's constant laid between $10^{-5} \sim 10^{-3}$, the resistance contribution from both the liquid and gas phase were significant; when the Henry's constant was between $10^{-7} \sim 10^{-5}$, the resistance from the gas phase dominated; however as Henry's constant $<3 \times$ $10^{-7}$, the evaporation rate would become slower than water. For scholars in volatility research, the Henry's constant is expressed by dividing the vapor pressure with the solubility, which indicated that as the value of Henry's constant became 
Table 1. Physical properties of VOCs.

\begin{tabular}{|c|c|c|c|c|c|}
\hline & $\begin{array}{c}\text { Evaporation } \\
\text { rate } \\
(\text { Butyl } \\
\text { acetate }=1)\end{array}$ & $\begin{array}{c}\text { Viscosity } \\
25^{\circ} \mathrm{C} \\
(\mathrm{cp})\end{array}$ & $\begin{array}{c}\text { Vapor } \\
\text { Pressure } \\
25^{\circ} \mathrm{C} \\
(\mathrm{mmHg})\end{array}$ & $\begin{array}{c}\text { Surface } \\
\text { tension } \\
25^{\circ} \mathrm{C} \\
(\mathrm{N} / \mathrm{m})\end{array}$ & $\begin{array}{c}\text { Density } \\
25^{\circ} \mathrm{C} \\
\left(\mathrm{kg} / \mathrm{m}^{3}\right)\end{array}$ \\
\hline Acetone & 7.2 & 0.306 & 230.687 & 0.0230 & 786.580 \\
\hline $\begin{array}{c}\text { Methyl } \\
\text { alcohol }\end{array}$ & 3.7 & 0.537 & 126.324 & 0.035 & 789.578 \\
\hline $\begin{array}{c}\text { Butyl } \\
\text { acetate }\end{array}$ & 1 & 0.678 & 11.503 & 0.024 & 876.064 \\
\hline $\begin{array}{c}\text { n-Pentyl } \\
\text { alcohol }\end{array}$ & 0.3 & 3.484 & 2.470 & 0.050 & 824.401 \\
\hline
\end{tabular}

higher, the evaporation rate was also higher [14].

The VOC fluids selected in the experiment were based by the different vapor pressure values, which were acetone, methyl alcohol, butyl acetate, and n-pentyl alcohol. The physical properties of the substances are listed in Table 1. Table 1 summarizes both surface tensions and the density $\rho$ of the test fluids at $25^{\circ} \mathrm{C}$. The surface tension was measured with a Du Nouy (DST30) and the density $\rho$ was measured with (DA-130N).

\section{Experimental Method}

In the early studies, Saffman and Geofffrey Taylor [17] captured the bubble profile by a camera while the bubble penetrating through a Hele-Shaw cell. They also superposed the profile of the bubble with $\lambda=0.87$ by a parametric equation. Taylor [20] observed the bubbles penetrating through three different diameter tubes filled with three different Newtonian fluid in an isothermal environment. He presented the relationship between $m$ and $C a$ to a single curve fitting. Ha-Ngoc and Fabre [6] simulated the shape of the bubbles with dimensionless parameters, such as length and height numerically. Sousa et al. [19] captured image of the bubble penetrating through the non-Newtonian fluid polyacrylamide (PAA) in a vertical tube by a CCD camera experimentally. They also plot the bubble profiles in some dimensionless parameters.

In this experiment, the gas is injected into tube filled with various VOCs in an isothermal environment. The volume rate of the injection gas was controlled by a mass flow controller in this experiment. The profile of the bubble is captured by a high-speed camera. The fractional converge of the liquid was estimated by these photographs. Fig. 2 shows a photo before the image processing and the ultimate graphics generated by the image processing. The width of the bubble was estimated by these images.

The photographs captured by the camera are processed by the image processing program written in the Matlab to measure the dimensions of the bubble accurately. In this study, the image is treated in a similar way as the method of Sousa et al. [19]. The image captured by the camera is processed by a post-processing program written in the Matlab. Some binarization and skeletonization skills are applied to eliminate the

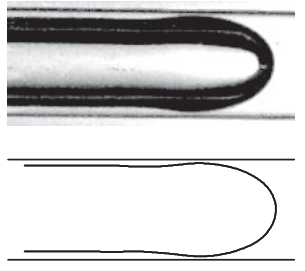

Fig. 2. Bubble image before and after processing.

errors caused by light shadow. The bubble profiles in some dimensionless parameters are plotted. The bubble profile information is obtained by using the Level Set Method. The measurement accuracy of this experiment is verified by the method shown in Yamamoto et al. [23]. Measured by The weight of fluid expelled by the bubble is weighed and denoted by $w$. The fractional converge $(m)$ of the bubbles is estimated by $m=1-\frac{w}{\rho \pi R_{0}^{2} L}$. Where $R_{0}$ is the radius of the tube, $L$ is the length of the tube. In this study, we study the impact of the various flow rates and various VOCs on the velocity (U) and the dimensionless parameters, such as the $C a, \operatorname{Re}, \lambda$ and $m$.

The dimensionless parameters are defined as:

$$
\begin{gathered}
C a=\frac{U \times \eta}{\sigma} \\
\operatorname{Re}=\frac{\rho \times U \times D}{\eta} \\
\lambda=\frac{R_{b}}{R_{0}} \\
m=\frac{R_{0}^{2}-R_{b}^{2}}{R_{0}^{2}}=1-\lambda^{2}
\end{gathered}
$$

where $U$ is the average velocity of the bubble $(\mathrm{m} / \mathrm{s}) ; \eta$ is the viscosity of the VOCs $(\mathrm{kg} / \mathrm{sec}-\mathrm{m}) ; \sigma$ is the surface tension of the VOCs $(\mathrm{mN} / \mathrm{m}) ; \rho$ is the density of the VOCs $\left(\mathrm{kg} / \mathrm{m}^{3}\right) ; D$ is the diameter of the circular tube $(m) ; R_{b}$ is the radius of the bubble $(m)$, and $R_{0}$ is the internal radius of the circular tube (m).

\section{RESULTS AND DISCUSSION}

\section{Relationship between $C a$ and $\boldsymbol{m}$}

To study the relation between $\mathrm{Ca}$ and $m$ for VOCs, the experiment conditions were as follow: Inlet gas injection diameter $=9 \mathrm{~mm}$, where $\mathrm{Q}$ was 600,400 and $200(\mathrm{ml} / \mathrm{min})$, respectively. When $\mathrm{Q}=600(\mathrm{ml} / \mathrm{min})$, the results are shown in Fig. 3. For the photography shooting of air bubbles at the three different positions, when the displacement distance of the bubbles increased, $\mathrm{Ca}$ also increased, but $m$ decreased. 


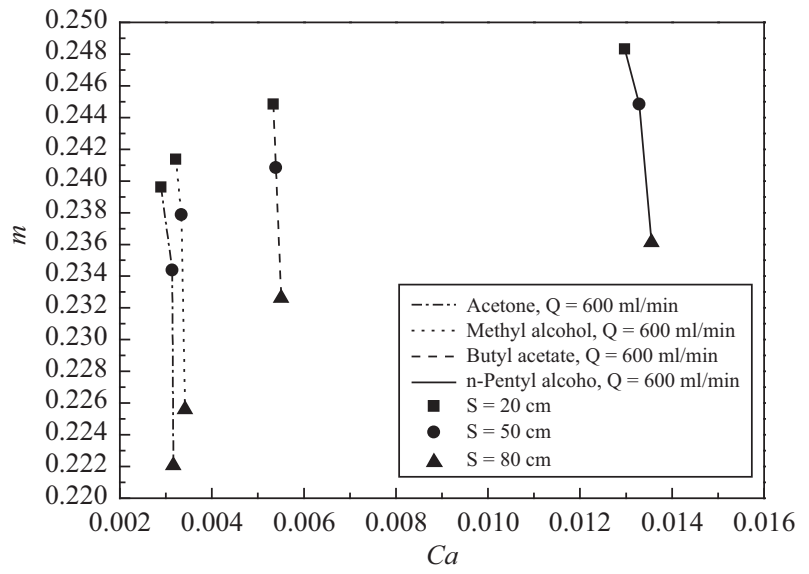

Fig. 3. The effect of $C a$ on $m$ when $Q=600 \mathrm{ml} / \mathrm{min}$.

From Table 1, it could be seen that n-pentyl alcohol has the slowest evaporation rate. However, comparing at the same position, the values of $C a$ and $\mathrm{m}$ were largest. Although acetone has the fastest evaporation rate, the values of $\mathrm{Ca}$ and $\mathrm{m}$ were lowest when compared at the same position. When the values of $\mathrm{m}$ difference (the difference between the maximum and minimum $m$ values) of the four VOCs in Fig. 3. were compared, as the shooting position moved from $\mathrm{S}=50 \mathrm{~cm}$ to $\mathrm{S}=$ $80 \mathrm{~cm}, m$ difference was largest, where acetone had the greatest difference at 0.012 , and n-pentyl alcohol had the smallest difference at 0.008 . The main reason was when long bubbles were within a solvent with a higher evaporation rate, the velocity of the bubbles increased as the displacement increased. Furthermore, the air bubble width quickly approached near the tube wall, and thus caused the $m$ value to quickly drop. When the long bubbles were within a solvent with a lower evaporation rate, the increment of bubble width dramatically reduces, and thus the drop of the $\mathrm{m}$ value becomes rather gradual. In addition, as the values of $\mathrm{Ca}$ difference for the 4 types of VOCs in Fig. 3. were compared, it was found that the $\mathrm{Ca}$ difference for solvents with a higher volatility, such as acetone and methyl alcohol, was not large; however a fluid with a lower volatility, such as n-pentyl alcohol, had a larger $\mathrm{Ca}$ difference value. The main reason was the viscosity of n-pentyl alcohol is significantly larger than the other three fluids, and therefore caused the $\mathrm{Ca}$ value to increase.

In Fig. 4, the gas flow was controlled at $\mathrm{Q}=400(\mathrm{ml} / \mathrm{min})$. The $\mathrm{m}$ difference values for acetone and methyl alcohol were apparently smaller than butyl acetate and n-pentyl alcohol. When the shooting position for butyl acetate and n-pentyl alcohol moved from $\mathrm{S}=20 \mathrm{~cm}$ to $\mathrm{S}=50 \mathrm{~cm}, m$ difference was the largest, where n-pentyl alcohol had the largest difference at 0.046; on the other hand, $m$ difference was largest for acetone and methyl alcohol when the shooting position moved from $\mathrm{S}=50 \mathrm{~cm}$ to $\mathrm{S}=80 \mathrm{~cm}$, where acetone had the largest difference at 0.013 . The cause for the difference above was mainly as the moving velocity of the bubble reached a certain critical value, the bubble width of the solvents with different

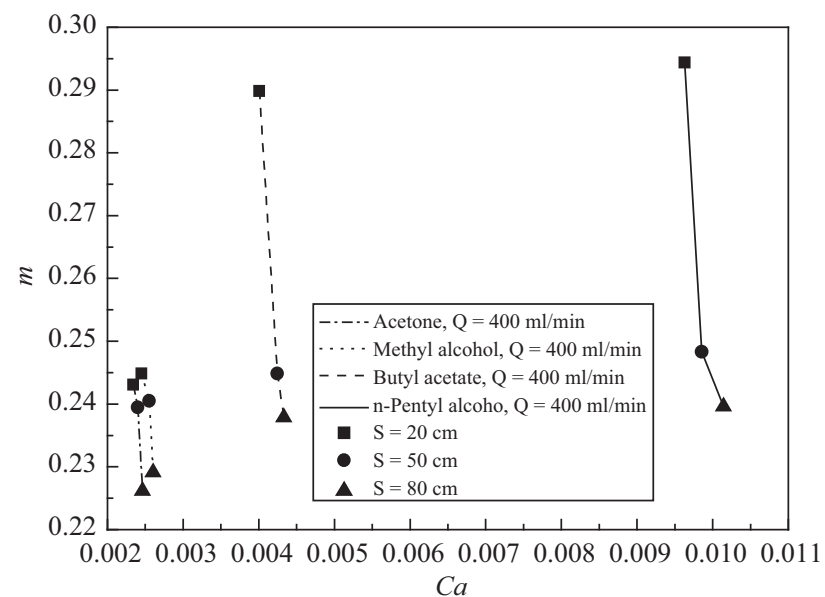

Fig. 4. The effect of $C a$ on $m$ when $Q=400 \mathrm{ml} / \mathrm{min}$.

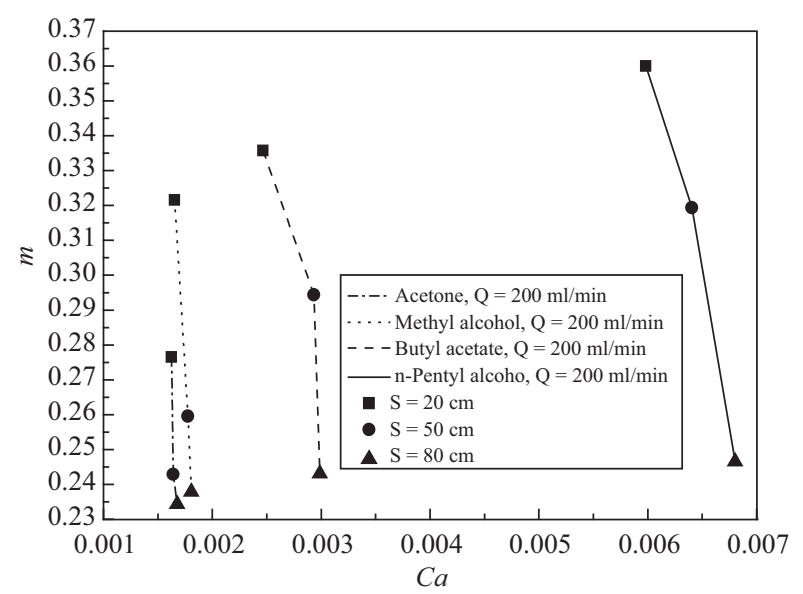

Fig. 5. The effect of $C a$ on $m$ when $Q=200 \mathrm{ml} / \mathrm{min}$.

evaporation rates varies. For fluids with higher volatilities, the width of the air bubble started to quickly enlarge at the beginning, and therefore the overall variation of the $m$ value was smaller; the bubble widths for solvents with smaller volatilities were smaller at the beginning, but when the bubbles reached $\mathrm{S}=80 \mathrm{~cm}$, the bubble width closely approached with the high-volatile VOC results, and therefore the overall variation of the $\mathrm{m}$ value was larger. As for the result of an equal $\mathrm{Ca}$ interval difference between Fig. 4 and Fig. 3, the main reason was due to the drop of the flow rate, which caused the bubble velocity to decrease, along with $\mathrm{Ca}$.

In Fig. 5, the flow rate was controlled at $\mathrm{Q}=200(\mathrm{ml} / \mathrm{min})$. When the shooting position of butyl acetate and n-pentyl alcohol moved from $\mathrm{S}=50 \mathrm{~cm}$ to $\mathrm{S}=80 \mathrm{~cm}$, the $m$ difference was largest, where n-pentyl alcohol had the largest difference at 0.0728; on the other hand, the $m$ difference was greatest for acetone and methyl alcohol when the shooting position moved from $S=20 \mathrm{~cm}$ to $S=50 \mathrm{~cm}$, where methyl alcohol had the largest difference at 0.062 . The reason was mainly caused by the factors of the liquid's evaporation rate and gas flow rate. 
As for the result of an equal $\mathrm{Ca}$ interval difference between Fig. 5 and Fig. 4, the main reason was due to the drop of the flow rate, which caused the bubble velocity to decrease, along with $C a$.

From the above descriptions, it can be summarized that regardless of the gas flow rate, as the displacement distance of the air bubbles increased within VOCs, the $m$ value shall decrease and the $\mathrm{Ca}$ value shall increase. For the $\mathrm{m}$ difference of the air bubbles between $\mathrm{S}=20 \mathrm{~cm}$ and $\mathrm{S}=80 \mathrm{~cm}$, the followings results were obtained:

a. Higher gas flow rates had greater influences toward the $m$ values for solvents with higher volatilities. For example, when $\mathrm{Q}=600(\mathrm{ml} / \mathrm{min})$, the $m$ difference for acetone reached its largest at 0.0175 , whereas the $m$ difference for $\mathrm{n}$-pentyl alcohol was the least at 0.0122 . Lower gas flow rates had a greater effect toward the $m$ values for the liquids with lower volatilities. For example, when $\mathrm{Q}=200(\mathrm{ml} / \mathrm{min})$, the $m$ difference for acetone was the least at 0.042 , while the n-pentyl alcohol had the largest difference at 0.113 .

b. While the gas injection flow rate was lower and when the moving bubble was at $\mathrm{S}=20 \mathrm{~cm}$, the $m$ value for the VOCs had a relatively larger difference; as the air bubble moved its position to $\mathrm{S}=80 \mathrm{~cm}$, the $m$ value for the VOCs significantly had a smaller difference. For example, when $\mathrm{Q}=$ $200(\mathrm{ml} / \mathrm{min})$, whereas the moving air bubble was at $\mathrm{S}=20$ $\mathrm{cm}$, the $m$ difference between acetone and n-pentyl alcohol was 0.083 . When the air bubble moved to $\mathrm{S}=80 \mathrm{~cm}$, the $m$ difference between acetone and n-pentyl alcohol was 0.012 .

c. When the gas injection flow rate was higher and the moving air bubble was at $\mathrm{S}=20 \mathrm{~cm}$, the $m$ value differences for the VOCs were relatively smaller. As the moving air bubble was at $\mathrm{S}=80 \mathrm{~cm}$, the $m$ values for the VOCs did not had a large difference when compared with the previous $Q=200$ ( $\mathrm{ml} / \mathrm{min})$. For example, when $\mathrm{Q}=600(\mathrm{ml} / \mathrm{min})$, and the bubble was at $\mathrm{S}=20 \mathrm{~cm}$, the $m$ difference of acetone and $\mathrm{n}$-pentyl alcohol was 0.008 . When the bubble was at $\mathrm{S}=80$ $\mathrm{cm}$, the $m$ difference between acetone and n-pentyl alcohol was 0.014 .

\section{Relationship between $\operatorname{Re}$ and $\lambda$}

In order to study the relation between $\operatorname{Re}$ and $\lambda$ for the VOCs, the flow rates Q were set at 600,400 and $200(\mathrm{ml} / \mathrm{min})$ respectively. When the flow rate $\mathrm{Q}=600(\mathrm{ml} / \mathrm{min})$, the results are as shown in Fig. 6. As the distance of the bubble increased, the values of $\operatorname{Re}$ and $\lambda$ increased along. The evaporation rate of acetone is the fastest, and when the same shooting position was compared, the values of $\operatorname{Re}$ and $\lambda$ were the largest. The evaporation rate of $n$-pentyl alcohol is the slowest, which comparison at the same position resulted with the lowest values of $\operatorname{Re}$ and $\lambda$. When the $\lambda$ difference values of the VOCs were compared at different shooting positions, it was found that $\lambda$ difference was greatest when the position moved from $\mathrm{S}=50 \mathrm{cmto} \mathrm{S}=80 \mathrm{~cm}$, where acetone had the largest difference at 0.01 , and n-pentyl alcohol had the least difference at

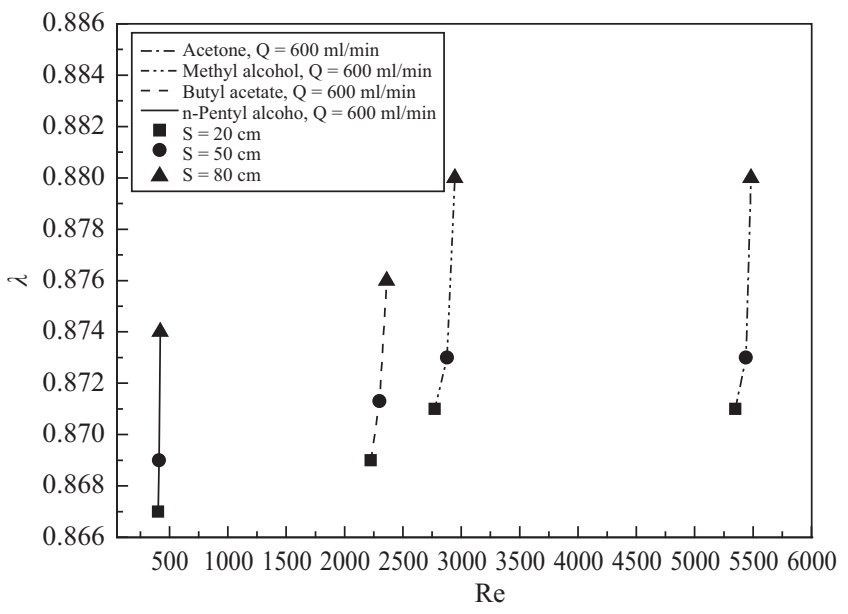

Fig. 6. The effect of $\operatorname{Re}$ on $\lambda$ when $Q=600 \mathrm{ml} / \mathrm{min}$.

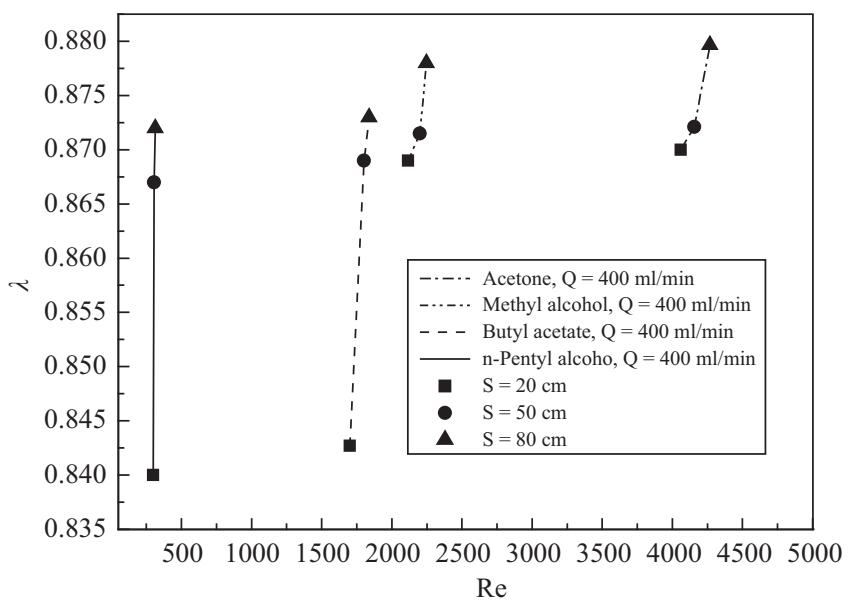

Fig. 7. The effect of $\operatorname{Re}$ on $\lambda$ when $Q=400 \mathrm{ml} / \mathrm{min}$.

0.007 . In addition, when the Re difference values were compared, the Re difference between methyl alcohol and butyl acetate was not large, whereas the Re difference between acetone and n-pentyl alcohol significantly increased. The main reason was that the viscosity value of n-pentyl alcohol was significantly larger than the other three fluids, and therefore the Re value became smaller.

In Fig. 7, where the gas flow rate was $400(\mathrm{ml} / \mathrm{min})$, the difference value between acetone and methyl alcohol was significantly less than butyl acetate with n-pentyl alcohol. When the shooting position for butyl acetate and n-pentyl alcohol moved from $\mathrm{S}=20 \mathrm{~cm}$ to $\mathrm{S}=50 \mathrm{~cm}$, the difference value of $\lambda$ was greatest, where n-pentyl alcohol had the largest difference at 0.027 ; when the shooting position for acetone and methyl alcohol moved from $\mathrm{S}=50 \mathrm{~cm}$ to $\mathrm{S}=80 \mathrm{~cm}$, the $\lambda$ difference value was the greatest, where acetone had the largest difference at 0.007 . As for the equal interval Re difference between Fig. 7 and Fig. 6, the main reason was caused by the flow rate drop, which caused the velocity of the bubble to decrease, and the Re value to drop along. 


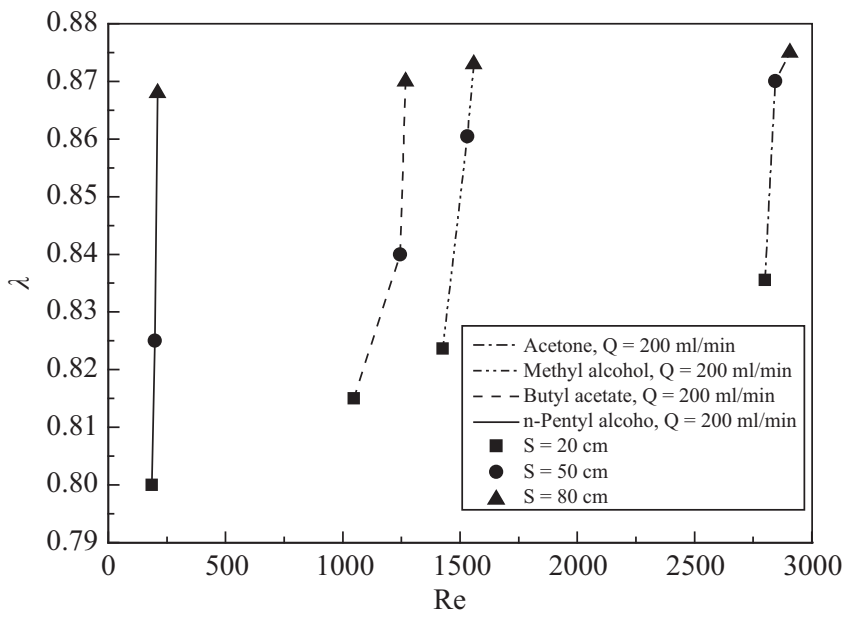

Fig. 8. The effect of $\operatorname{Re}$ on $\lambda$ when $Q=200 \mathrm{ml} / \mathrm{min}$.

The gas flow rate in Fig. 8 was $200 \mathrm{ml} / \mathrm{min}$. As the shooting positions for butyl acetate and n-pentyl alcohol moved from $\mathrm{S}=50 \mathrm{~cm}$ to $\mathrm{S}=80 \mathrm{~cm}, \lambda$ difference was the greatest, where n-pentyl alcohol had the greatest difference at 0.043 ; on the other hand, the value difference of $\lambda$ was greatest when the shooting positions for acetone and methyl alcohol moved from $\mathrm{S}=20 \mathrm{~cm}$ to $\mathrm{S}=50 \mathrm{~cm}$, where methyl alcohol had the largest difference at 0.037. As for the equal interval Re difference between Fig. 8 and Fig. 7, the main reason was caused by the flow rate drop, which caused the velocity of the bubble to decrease, and the Re value to drop along.

\section{Bubble Profiles}

The earliest photographing in regards with bubble shapes was done by Saffman and Geofffrey Taylor [17]. By using a flat plate mode, Saffman was able to shoot the air bubble shapes of water penetrating oil and oil penetrating glycerin. There is little research regarding the temporary status phenomenon of long bubble within VOCs. This study used four different volatile solvents, acetone, methyl alcohol, butyl acetate and n-pentyl alcohol, and used MFC to control three different gas flow rates, to observe the shape variation of the bubbles. During the experiment, only when the evaporation rate of the solvent is fast and the moving velocity of the bubbles were within a certain region, did the bubble shape had significant changing. This bubble shape was different than the commonly seen bubble shape, and therefore was defined as a "mushroom bubble". The two main factors which resulted with this mushrooms bubble phenomenon was determined by the evaporation rate of the VOCs and the variation with the Re value. It was found in the experiment that besides n-pentyl alcohol, the other three types of solvents would all create mushroom bubbles. Fig. 9 shows the continuous mushroom bubble variation plot of acetone, methyl alcohol, and butyl acetate, and the ranges of the $\mathrm{Re}$ and $\mathrm{Ca}$ values during this produced temporary status. From the Fig. 9, it could be seen that as acetone had the highest evaporation rate, the formed

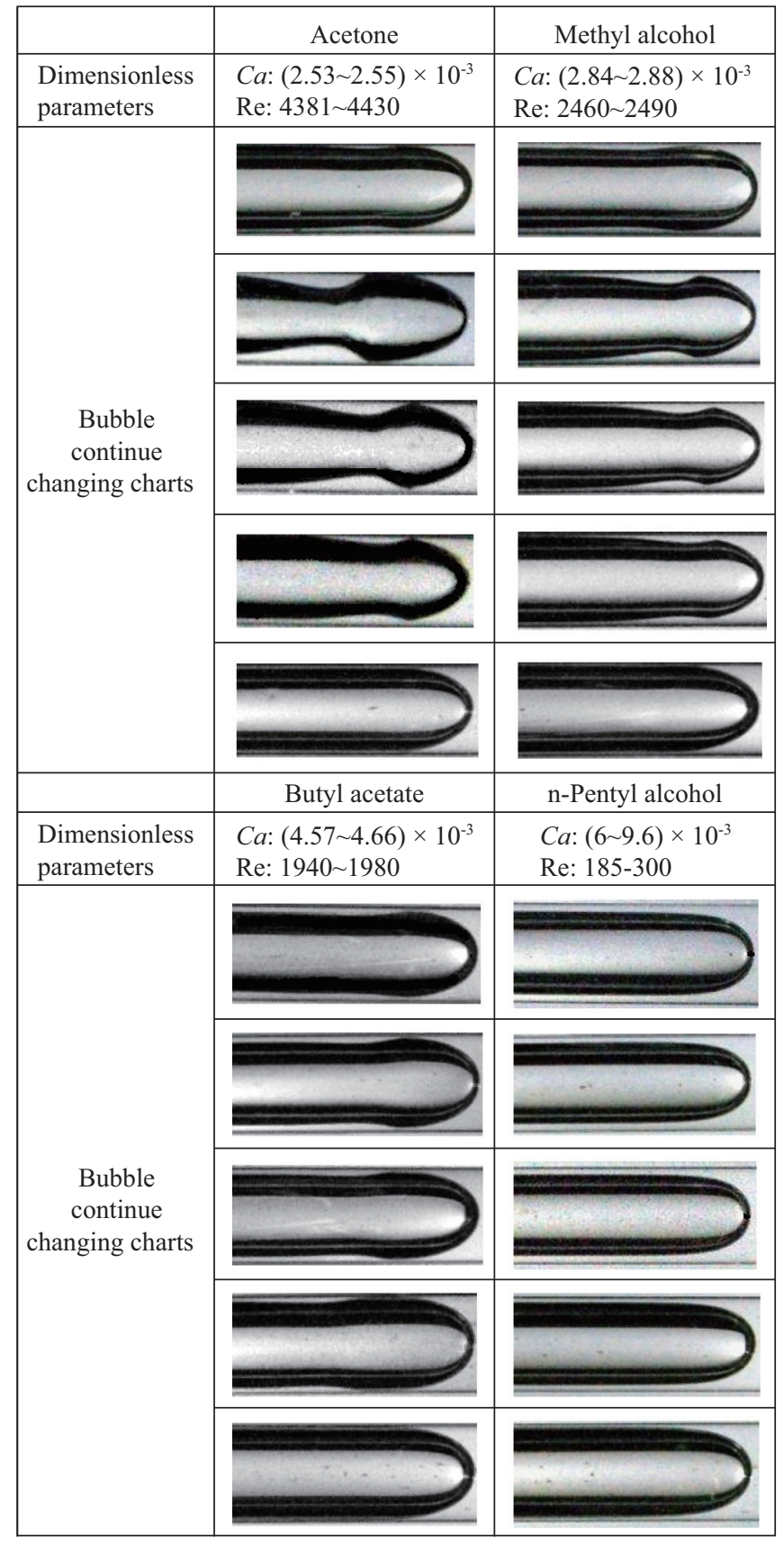

Fig. 9. Evolution of bubble contours with the scope of the dimensionless parameters.

mushroom bubbles were more apparent. At the very moment, the Re value was largest, but the $C a$ value was smallest. The evaporation rate of n-pentyl alcohol was the lowest, and would not create mushroom bubbles. However, the bubble width gradually became wider, and the bubble would finally nearly approach the walls of the tube. At this very moment, the Re value was at its minimum, where the $C a$ value was at its maximum. With the comparison of the four different solvents, it could be realized that as the solvent evaporation rate $\geqq 1$, mushroom bubbles would occur when $\mathrm{Ca}$ and Re were within 


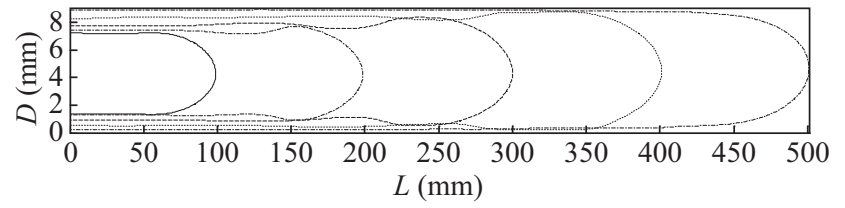

Fig. 10. Bubble shape continuous variation in butyl acetate for $Q=400$ $\mathrm{ml} / \mathrm{min}$.

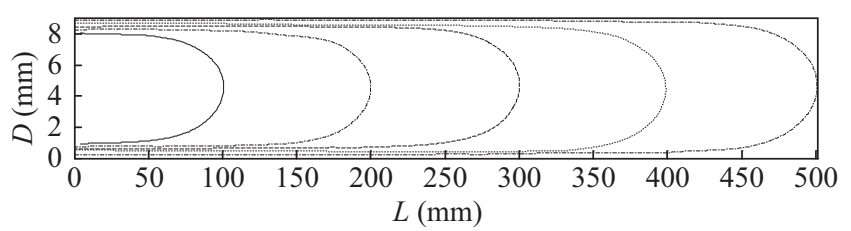

Fig. 11. Bubble shape continuous variation in n-pentyl alcohol for $Q=$ $300 \mathrm{ml} / \mathrm{min}$.

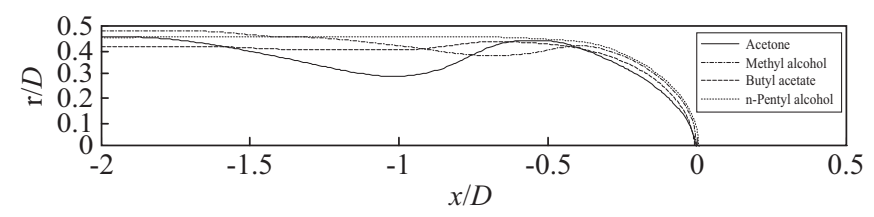

Fig. 12. Evolution of the dimensionless bubble contours.

a certain range. Furthermore, the air bubbles would follow by attaching with the tube wall. When the solvent's evaporation rate $<1$, mushroom bubbles would not occur, which the bubble width widens slowly. The air bubbles eventually also would nearly attach to the wall.

The photographs of the Figs. 10-12 are processed by the image processing program written in the Matlab. The bubble profile information can be obtained by using the Level Set Method. Fig. 10 shows the continuous bubble shape variation with the condition of butyl acetate at a certain Q $(400 \mathrm{ml} / \mathrm{min})$, where the gas was injected from the left side of the test tube. The horizontal axis represents the bubble's moving distance, and the vertical axis represents the diameter changes of the bubble. From the continuous plot, it could be realized as the bubble moves to $\mathrm{S}=200 \mathrm{~mm}$, mushroom bubble start to form. Following, the head side of the bubble enlarges, and finally the bubble width nearly attaches the tube wall. Fig. 11 shows the continuous bubble shape variation with the condition of n-pentyl alcohol at a certain Q $(300 \mathrm{ml} / \mathrm{min})$, where the gas was injected from the left side of the test tube. The representations of the horizontal and vertical axis were the same as the prescription of above. Since n-pentyl alcohol has a low evaporation rate, therefore mushrooms bubbles would not occur. However, the bubble width would gradually increase with the increasing of the bubble's displacement distance. Finally, the bubble width would also nearly attach to the tube wall. The stack plot of Fig. 12 was by taking the third changing of each solvent in Fig. 9, and by using the level set method of Matlab, the original photos were thinned and skeletonized.

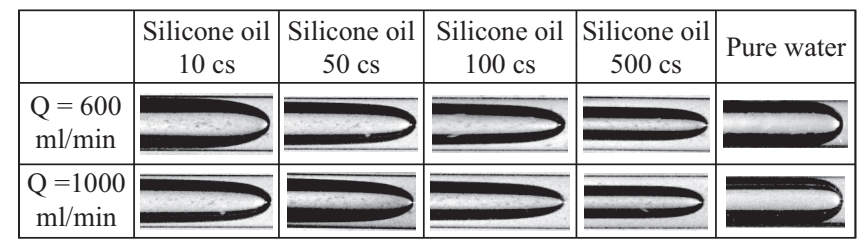

Fig. 13. Bubble images in water and silicone oil with various gas flows.

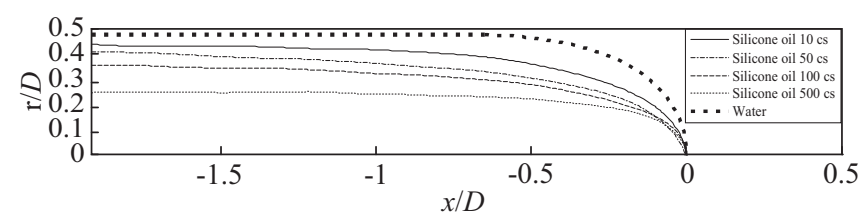

Fig. 14. Dimensionless bubble contours in water and silicone oil for $Q=$ $1000 \mathrm{ml} / \mathrm{min}$.

The horizontal axis and vertical axis represent the bubble's moving distance and the dimensionless parameter of the bubble's diameter divided by the diameter of the tube, respectively. From the Fig. 12, it could be seen that solvents with a higher evaporation rate forms mushroom bubbles with a more apparent shape.

In order to compare the shapes between the mushroom bubbles and the commonly seen long bubbles, the experiment increased 5 types of silicone oil and distilled water fluids, which the viscosity were $10 \mathrm{cs}, 50 \mathrm{cs}, 100 \mathrm{cs}$ and $500 \mathrm{cs}$ respectively. The shooting position was selected at the middle of the tube $(\mathrm{S}=50 \mathrm{~cm})$. MFC were used to control for two different flow rates of Q (1000 and $600 \mathrm{ml} / \mathrm{min})$. Fig. 13 is the bubble shape plot of different combinations of silicone oil viscosities with water at different gas flow rates. From the plot, it could be seen that no matter how the gas flow rate of the distilled water tube had changed, the bubble width nearly was attached to the tube wall. In addition, the curve ratio changes of the bubble head shape were not large. For silicon oil, the change of the gas flow rate would cause significant changes with the head shape of the bubble and its curve ratio. When the viscosity of the silicon oil was less than $500 \mathrm{cs}$, and as the injection gas flow rate was smaller, the bubble width was larger and the curve ratio of the bubble's head was larger. This was especially most apparent when the viscosity of the silicon oil was $10 \mathrm{cs}$. When the viscosity of silicon oil was greater than $500 \mathrm{cs}$, the changing with the injection gas flow rate did not have much influence with the bubble width and curve ratio of the bubble's head. The stack plot of Fig. 14 was with the Q condition $(1000 \mathrm{ml} / \mathrm{min})$ in Fig. 13, where the original photos were thinned and skeletonized by using the level set method of Matlab. The horizontal axis and vertical axis represents the bubble's moving distance and the dimensionless parameter of the bubble's diameter divided by the diameter of the tube, respectively. From Fig. 14 and Fig. 12, it could be seen that the long bubble shape within general Newton liquids and VOCs have a significant difference. 
Table 2. Parameters of the bubble shape equation.

\begin{tabular}{|c|c|c|c|c|}
\hline & Acetone & $\begin{array}{c}\text { Methyl } \\
\text { alcohol }\end{array}$ & $\begin{array}{c}\text { Butyl } \\
\text { acetate }\end{array}$ & $\begin{array}{c}\text { n-Pentyl } \\
\text { alcohol }\end{array}$ \\
\hline a1 & 0.769 & 0.849 & 1.023 & 0.833 \\
\hline b1 & 1.642 & 1.633 & 1.701 & 1.589 \\
\hline c1 & -2.527 & -2.571 & -2.474 & -2.618 \\
\hline a2 & 0.494 & 0.507 & 0.677 & 0.464 \\
\hline b2 & 2.521 & 2.445 & 2.348 & 2.415 \\
\hline c2 & 1.735 & 1.558 & 1.525 & 1.606 \\
\hline a3 & 0.017 & 0.048 & 0.032 & 0.034 \\
\hline b3 & 5.568 & 5.454 & 5.170 & 5.608 \\
\hline c3 & -2.899 & 2.453 & 2.071 & 2.565 \\
\hline a4 & 0.014 & 0.009 & 0.012 & 0.012 \\
\hline b4 & 7.998 & 8.428 & 8.710 & 8.391 \\
\hline c4 & 1.304 & -2.794 & 2.979 & 2.848 \\
\hline a5 & 0.008 & 0.004 & 0.009 & 0.006 \\
\hline b5 & 11.2 & 11.25 & 11.220 & 11.17 \\
\hline c5 & 3.124 & 3.057 & 3.151 & 3.101 \\
\hline $\begin{array}{c}\text { Root Mean } \\
\text { Square } \\
\text { Error (RMSE) }\end{array}$ & 0.006 & 0.009 & 0.010 & 0.008 \\
\hline
\end{tabular}

\section{Bubble Shape Equation}

Saffman and Geofffrey Taylor [17] was the first to propose the shape equation of air bubbles for Newton fluids. In addition, the bubble shape was drawn based with the equation for $\lambda=0.55$. Pitts [16] modified the bubble shape equation of Saffman and Geofffrey Taylor [17], and used the equation to predict the air bubble shape for $\lambda=0.77$. As for the air bubble equation descriptions for non-Newton fluids, Sousa et al. [19] used dimensionless analysis with carboxy methyl cellulose (CMC) to describe the shape of air bubbles. This study was based on Sousa et al. [19] model, where the VOCs bubble shapes in Fig. 12 used Matlab curve fitting sum of sine functions to describe the air bubble shape. The equation is expressed as follow

$$
F(x)=\sum_{i=1}^{5}[a i \times \sin (b i x+c i)]
$$

$\mathrm{a}$ is the amplitude, $\mathrm{b}$ represents the frequency, and $\mathrm{c}$ indicates the phase. Table 2 gives the list the coefficient for each term and its root mean square error (RMSE) for the four different VOCs after simulation. When the coefficients during the mushroom bubble production for acetone, methyl alcohol, and butyl acetate were compared, it was seen that the volatility of acetone was the highest and created the most significant mushroom bubbles; butyl acetate had the lowest volatility, and the produced mushroom bubbles were not significant. At that time, the coefficient values of a1, b1, c1, a2, and b4 were highest for butyl acetate and lowest for acetone. On the other hand, the b2, c2 and b3 coefficient values were highest for acetate and lowest for butyl acetate.

\section{CONCLUSION}

In this study, the straight tubes were filled with VOCs, and MFC were used to control the injection amount of different gases into the straight tubes. The long bubbles will occur with a temporary status phenomenon within the tube. From the experimental test results, the following conclusions were made:

a. During round tube tests, the photography shooting was performed at 3 different positions. It was found as the displacement distance of an air bubble increased, the $\mathrm{Ca}$, Re, and $\lambda$ values also increased, whereas $m$ decreased. Although acetone had the fastest evaporation rate, compared at the same shooting position, the $C a$ and $\mathrm{m}$ values were the lowest, whereas the values of Re and $\lambda$ were the largest.

b. When the gas flow rate was lower, and while the air bubbles moved their position nearby the entrance, the $m$ difference values for the VOCs were larger; as the air bubbles moved their position near the exit, the difference significantly became smaller in regards with the $m$ difference of the VOCs.

c. When the gas flow rate was higher, $m$ difference was higher for high-volatile VOCs; for VOCs with lower volatility, the $m$ difference values were lower.

d. When VOCs evaporation rate $<1$, the mushrooms bubble phenomenon did not occur, regardless of how the Re values of the moving air bubbles had changed. As an example with n-Pentyl alcohol, as $\operatorname{Re}<185$, the $m$ difference value of the air bubble was not large; when Re value $>185$, the air bubble width would apparently increase, and the $\mathrm{m}$ difference value would enlarge.

e. When evaporation rate of VOCs $\geqq 1$, the mushrooms bubble shall occur as the Reynolds number (Re) of the moving air bubbles reaches a certain region. From the result of the experiments, it was known as the Re value for acetone, methyl alcohol and butyl acetate was between 4381 4430, 2460 2490 and 1940 1980, respectively, mushrooms bubble occurred. Moreover, the shapes of the produced mushrooms bubble were more apparent when volatility of the solvent was higher. In addition, when the Re value of the air bubbles movement for the three VOCs exceeded the zone for mushrooms bubble formation, the bubble width shall rapidly attach near to the tube wall, and no mushrooms bubble phenomenon would occur.

\section{REFERENCES}

1. Cox, B. G., "On driving a viscous fluid out of a tube," Journal of Fluid Mechanics, Vol. 14, pp. 81-96 (1962).

2. Cox, B. G., "An experimental investigation of the streamlines in viscous fluids expelled from a tube," Journal of Fluid Mechanics, Vol. 20, pp. 193-200 (1964).

3. Fairbrother, F. and Stubbs, A. E., "Studies in electro-endosmosis. Part VI. The bubble-tube method of measurement," Journal of Chemical Society, Vol. 1, pp. 527-529 (1935).

4. Gauri, V. and Koelling, K. W., "Gas-assisted displacement of viscoelastic fluids: flow dynamic at the bubble front," Journal of Non-Newton Fluid Mechanics, Vol. 83, pp. 183-203 (1999). 
5. Giavedoni, M. D. and Saita, F. A., "The axisymmetric and plane cases of a gas phase steadily displacing a Newtonian liquid: A simultaneous solution of the governing equations," Physics of Fluids, Vol. 9, pp. 2420-2428 (1997).

6. Ha-Ngoc, H. and Fabre, J., “A boundary element method for calculating the shape and velocity of two-dimensional long bubble in stagnant and flowing liquid," Engineering Analysis with Boundary Elements, Vol. 30, pp. 539-552 (2006)

7. Hsu, C.-H., Chen, P.-C., Kung, K.-Y., and Lai, C., "Impacts of ratio of asymptotic bubble width to diameter of circular tube and Reynolds number in a gas bubble driven flow," Chemical Engineering Science, Vol. 60 , pp. 5341-5355 (2005).

8. Huzyak, P. C. and Koelling, K. W., "The penetration of a long bubble through a viscoelastic fluid in a tube," Journal of Non-Newton Fluid Mechanics, Vol. 1, pp. 73-88 (1997).

9. Janghoo, S., Shinsuke, K., Yuji, A., and Satoko, C., "Performance test for evaluating the reduction of VOCs in rooms and evaluating the lifetime of sorptive building materials," Building and Environment, Vol. 44, pp. 207-215 (2009).

10. Kobayashi, T., Shimizu, Y., and Urano, K., "Estimation of adsorbed amounts of volatile chlorinated organic compounds to wet soil based on the properties of the compounds and soils," The Science of the Total Environment, Vol. 301, pp. 215-223 (2003).

11. Kolb, W. B. and Cerro, R. L., "Coating the inside of a capillary of square cross section," Chemical Engineering Science, Vol. 46, pp. 2181-2195 (1991).

12. Lalanne, F., Malhautier, L., Roux, J. C., and Fanlo, J. L., "Absorption of a mixture of volatile organic compounds (VOCs) in aqueous solutions of soluble cutting oil," Bioresource Technology, Vol. 99, pp. 1699-1707 (2008).

13. Mackay, D. and Leinonen, P. J., "Rate of evaporation of low-solubility contaminants from water bodies to atmosphere," Environmental Science \&
Technology, Vol. 9, pp. 1178-1180 (1975).

14. Mackay, D. and Shiu, W. N., "A critical review Henry's law constants for chemicals of environmental interest," Journal of Physical and Chemical Reference Data, Vol. 10, pp. 1175-1199 (1981).

15. Oliveira, T. A. C., Scarpello, J. T., and Livingston, A. G. "Pervaporation-biological oxidation hybrid process for removal of volatile organic compounds from wastewaters," Journal of Membrane Science, Vol. 195, pp. 75-88 (2002).

16. Pitts, E., "Penetration of fluid into a Hele-Shaw cell: the Saffman-Taylor experiment," Journal of Fluid Mechanics, Vol. 97, pp. 53-64 (1980)

17. Saffman, P. G. and Geofffrey Taylor, F. R. S., "The penetration of a fluid into a porous medium or Hele-Shaw cell containing a more viscous liquid," Proceedings of Royal Society, Vol. A 245, pp. 312-329 (1958).

18. Schwartz, L. W., Princen, H. M., and Kiss, A. D., "On the motion of bubbles in capillary tubes," Journal of Fluid Mechanics, Vol. 172, pp. 259-275 (1986).

19. Sousa, R. G., Riethmuller, M. L., Pinto, A. M. F. R., and Campos, J. B. L. M., "Flow around individual Taylor bubbles rising in stagnant polyacrylamide (PAA) solutions," Journal of Non-Newton Fluid Mechanics, Vol. 135, pp. 16-31 (2005).

20. Taylor, G. I., "Deposition of a viscous fluid on the wall of a tube," Journal of Fluid Mechanics, Vol. 10, pp. 161-165 (1960).

21. Wong, H., Radke, C. J., and Morris, S., "The motion of long bubbles in polygonal capillaries. Part 1. Thin films," Journal of Fluid Mechanics, Vol. 292, pp. 71-94 (1995a).

22. Wong, H., Radke, C. J., and Morris, S., "The motion of long bubbles in polygonal capillaries. Part 2. Drag fluid pressure and fluid flow," Journal of Fluid Mechanics, Vol. 292, pp. 95-110 (1995b).

23. Yamamoto, T., Suga, T., Nakamura, K., and Moti, N., "The gas penetration through viscoelastic fluid with shear-thinning viscosity in a tube," Transactions of the ASME, Vol. 126, pp. 148-152 (2004). 